\title{
Dynamics of Drought-Related Migration among five villages in the Savannah of Ghana
}

Francis Xavier Jarawura

\begin{abstract}
For many households in rural sub-Saharan Africa, drought is an important environmental shock because it undermines livelihoods and wellbeing. There is a growing concern that droughts in the context of a changing climate could magnify migration out of rural areas. Using an exploratory mixed method approach, this paper explores the relationship between drought and migration in five villages in the northern savannah of Ghana. The results suggest that drought-related migration in the savannah is much about rural to rural migration as it is about rural to urban migration. This observation contrasts with the concentration of the literature on the possibilities and outcomes of climate-induced rural to urban migration. The study further highlights the mediating role of a range of idiosyncratic factors in the migration responses to drought. A multivariate analysis showed that selected individual, household, and village variables explain about $21.5 \%$ of drought-related migration. The qualitative results revealed additional mediating factors notably; individual aspirations, the effect of pull factors and networks. Thus, drought-related migration is not always about vulnerability and responses as commonly viewed, but intricately intertwined with the socio-economic and political dynamics of people. The multiplicity of factors and the complexity of their interaction clearly show the need to shift away from simplistic and deterministic notions of the climate-migration nexus.
\end{abstract}

Key words: Drought, Environment, Climate Change, Migration.

University of Business and Integrated Development Studies-Wa, Ghana. Email: jarawura@yahoo.com

Ghana Journal of Geography Vol. 13 (1), 2021 pages 103-125

https://dx.doi.org/10.4314/gig.v13i1.6 


\section{Introduction}

In Africa, high reliance on rainfall and ecosystem resources exposes households to the consequences of drought. The most immediate impacts of droughts on rural livelihoods are therefore felt in the areas of crop and animal production, which have consequential implications on household and national food security (Devereux, 2000; Adaawen et al., 2019) and other livelihood outcomes including health, education and peace (Ellis, 2000). The consequences of droughts are magnified by deep rural poverty, limited government capacity, and an exposure to additional political, economic and health shocks (IPCC, 2013). One common response to drought in Sub-Saharan Africa is migration (Hugo, 1996; Thiede et al., 2016) and there is growing concern that climate change will magnify this process through increased occurrence and intensity of droughts (IPCC, 2013; Liehr et al., 2016). This concern straddles predictions and actual empirical findings of drought-migration linkages (Foresight, 2011; Liehr et al., 2016). The quantitatively based predictions particularly, have been criticised for various reasons including the reliance on sparse documentation (Black et al., 2011) and the failure to recognise the role of human agency resulting in mechanistic approaches (Foresight, 2011; Jarawura \& Smith, 2015). Empirical studies on the subject on the other hand, especially of multivariate nature, are rare albeit receiving appreciable attention in recent times. A major reason for the paucity of empirical studies is that environment-migration linkages are complex and difficult to unravel in the midst of the interplay of multiple environmental and other drivers of migration (Black et al., 2011; Liehr et al., 2016).

The difficulty in explaining the nexus between the environment and migration flows is reflected both in the theoretical and empirical landscape on migration. So far, there is no single theory that has provided a comprehensive understanding of migration decisions and outcomes (Van der Geest, 2011). There are numerous overlapping theories with varying explanatory capabilities. Environmental push and pull perspective can be very useful in explaining migration flows but it equally comes with fundamental flaws. The key notion of push-pull perspective is that unfavourable environmental conditions such as soil infertility, declining rainfall and recurrent drought can act to push people out of their home while pull factors such as favourable climate and soil conditions will in turn attract them to a new location. While this turns out to be a useful starting point to understanding migration flows, it has proven to be problematic as push-pull factors rarely act alone. Critical factors to consider are human agency and aspiration (Foresight, 2011) and the role of networks (Van der Geest, 2011). Human agency and aspiration are distinct factors that reside in people and critical in decision making. 
Networks have proven to be crucial in determining particularly where a migrant chooses to go. Notwithstanding the difficulty in establishing causality and explaining the role of the environment, studies reveal some critical linkages between drought and migration. Droughts have been found to contribute to increases in migration flows from rural areas as inhabitants seek other sources of income and food (Cleveland, 1991; Krokfors, 1995; IPCC, 2013). Other studies, however, show that droughts do not always result in a general increase in migration from rural areas but may trigger changes in migration patterns including shifts from longdistance to short-distance circulation and from longer to shorter stays away from home (Findley, 1994; Schoumaker \& Beauchemin, 2004) and changes in gender patterns as well (Findley, 1994). The literature shows the importance of drought for migration but also reveals that household and individual responses to drought as in migration are more complex than commonly assumed. This relates to the multiplicity and complex interaction of different factors in the decision to migrate. Thus, the paucity of empirical work on the association between drought and migration extends to the factors that mediate drought-related migration flows under changing climate conditions (Gray \& Muller, 2012; Liehr et al., 2016).

This current study investigates the nexus between drought and migration as well as the factors that mediate migration flows from drought conditions in five villages in the savannah of northern Ghana. The savannah of Ghana is of interest for this study because of its proneness to droughts, widespread yet enduring poverty and relatively long history of migration. According to the Environmental Protection Agency of Ghana (EPA, 2012), the zone is characterised by high rainfall variability and frequent droughts. The effects of climate change are also felt greatest in this part of the country through rising rainfall variability, rising frequency of droughts and floods, short spells and increasing unpredictability of rainfall. Meanwhile the ecological zone has a uni-modal rainfall regime thereby concentrating drought risks in a single season as compared to two seasons in the transitional agro-ecological zone and the forest zone, both of which cover much of the southern part of the country (Dietz et al., 2004). The effects of these physical features are enhanced by deeply rooted and widespread poverty (Van der Geest, 2011; Yaro et al., 2016; Derbile et al., 2016). According to the Ghana Statistical Service (GSS, 2018) poverty has been more widespread and persistent in the zone than other parts of Ghana. Indeed, it is the only ecological zone in the country to register an increase in poverty of living below $240 \$$ per adult per annum, between the years 2012/2013 and 2016/2017. This situation is even more profound in the rural parts of the savannah where nearly two-thirds 
$(67.7 \%)$ of the people are poor (GSS, 2018). Climate change projections for Ghana generally suggest that the savannah will endure most of the changes in patterns of rainfall. The general notion is that the savannah will experience increasing dryness through reducing rainfall and higher frequency of droughts (Yaro, 2013). This is expected to increase migration flows from the area (Jarawura \& Smith, 2015). Modern migration in the savannah is rooted in the colonial history of Ghana when deliberate development strategies were used to impoverish northerners and ensure their migration to mines and plantations located in the south (Bening, 1975). The development imbalance created still persist and thus crucial in migration flows from the region with the exacerbation of environmental challenges. The northern savannah has consistently been the region with the highest out-migration (GSS, 2018). However, the roles of environmental drivers in this process have received little attention (Van der Geest, 2011, Jarawura \& Smith, 2015).

The next section of the paper presents the theoretical framework of the study. The third section presents the methodology of the study, which encapsulates the context of the study and the source(s) of data. This is followed by the presentation of the results on the role of drought in migration and the mediation factors influencing drought-related migration. The last section concludes the paper.

\section{Theoretical framework}

There is no single theoretical framework that has been successful in providing a comprehensive understanding of the role of the environment in the migration of people. Given the complexity and the interactions of the various drivers of migration with environmental factors, a framework that encapsulates broader dimensions of the migration process is required. This paper adopts the Foresight (2011) conceptual framework, which stipulates that the decision to migrate is influenced by five broad categories of drivers. As shown in Figure 1, these drivers are set out at the vertices of the pentagon; environmental, social, economic, demographic, and political. 


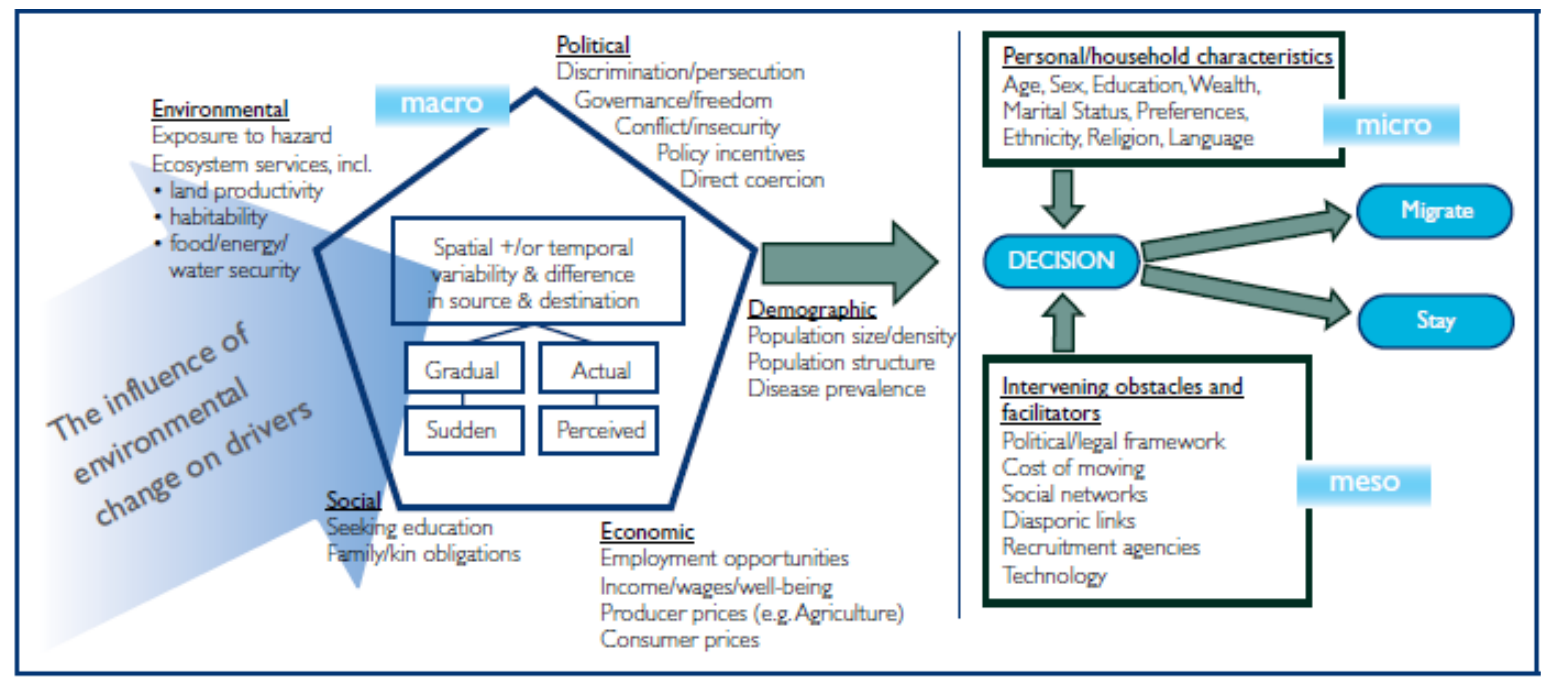

Figure 1. Foresight conceptual framework; drivers' of migration and the influence of environmental change

The framework recognises that migration in most parts of the world results from the interaction of these drivers. Thus, environmental change will influence migration outcomes by affecting existing drivers of migration (Foresight, 2011). However, migration decisions are not only shaped by the complex interplay of these broad drivers, but by intervening factors and personal and household characteristics at the meso and micro-levels. Thus, whether migration will occur or not, depends on the outcome of the mediation of community, households and individual factors. Recognising that not all affected households or individuals will migrate is a very important context for understanding the nexus between environmental change and migration. For example, individuals and households may be constrained to migrate because of the lack of social, economic and human capital when confronted by lower productivity from droughts. Also, in instances where environmental change causes erosion of assets, migration will be less likely (Foresight, 2011). The Foresight framework, thus, encapsulates broader dimensions of the different theoretical explications of migration including push and pull factors as well as capability of individuals and households that can enable a better understanding of the dynamics of drought-related migration. Accordingly, an assessment of the influence of drought on migration in the rural savannah will have to recognise the interplay of broader level factors, meso-level factors and micro level factors as well as the direction of migration flows. The broader perspective of the Foresight conceptual framework makes it appropriate to this study as it allows for a holistic appreciation of the dynamics of drought-related migration. This paper, gives priority to the selection of village, household and individual variables that will help understand migration responses to drought. 


\section{Research Methodology}

The research examined the relationship between drought and migration in five villages in the Savelugu district of the Northern Region of Ghana. As shown in figure 2, the study villages include Kpalung, Laligu, Tunaayili, Libga and Zaazi, all located in the Savelugu district, which was previously part of the Savelugu/Nantong District Assembly. These villages are typically agrarian with minimal non-farm activities as weaving, carpentry, masonry and processing of agro products. The villages of Libga and Zaazi are however, privileged to have the possibilities for dry season gardening as they share a common irrigation scheme. This difference between the two villages and the others might be crucial in discerning differences in drought-related migrations as the latter might be better placed to absorb drought impacts than the former.

The paper employed an exploratory mixed method approach where an initial phase of qualitative data collection and analysis is followed by a quantitative data collection and analysis, and then an integration of the analysis. Exploring the nature of drought-related migration requires intimate conversations. This makes it prudent to start with conversations around community, household and individual migration experiences. Focus group discussions and individual interviews were employed for this purpose. The qualitative component largely centred on the reasons for migration and the role of various non-drought factors in mediating migration outcomes from drought circumstances. Two focus groups with 9 to 12 participants were held in each village, one conducted with household heads and another with young people. Ten individual interviews were also conducted with return and circular migrants. The ten people were purposively selected for their experiences in migration. 


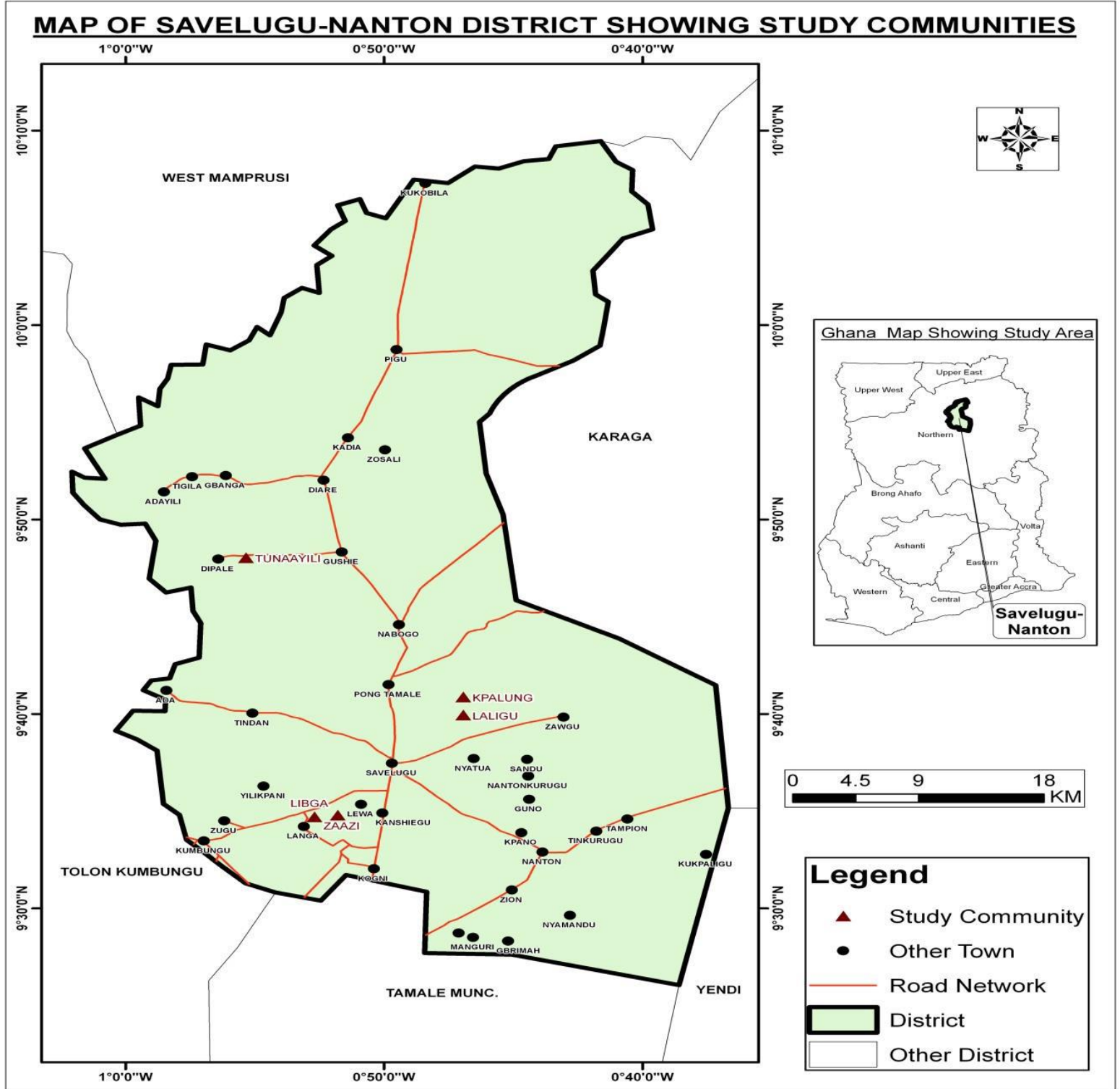

Figure 2. Map of the study villages

The survey involved 200 households representing two-third of the total household population of the study villages. The researcher arbitrarily decided to administer the survey to two-third of the household population to increase the chances of obtaining a more representative picture of the role of drought in migration as well as the factors influencing migration decisions under drought circumstances. The questionnaires were administered to individuals in the 200 households to solicit both individual specific and household variables relating to migration. The simple random sampling method, through balloting, was used to select households and household members. A listing of households and their members (ten years and above) was conducted allowing the researcher to perform a simple random selection. One individual was 
selected randomly from the list. For those within the ages of 10-14, their parents were asked to provide answers to the questions in the presence of the children as in all cases the children were taken along by these parents. The results of this paper are limited in terms of explaining the permanent migrations from the villages. This is because the data used in this work is from only respondents in the origin that have previously or were currently experiencing migration.

\section{Dependent and independent Variables}

The dependent variable was measured by asking respondents who had migrated before or still involved in the process within the last ten years whether their migration(s) was/were droughtrelated or not. In all, 200 households were selected randomly from the listing of households in the study communities that was done as part of the study. One member of each of the 200 selected households was selected on random basis from a listing of household members aged 10 years and older and interviewed about his or her migration experiences for the last ten years. Out of the 200 individuals from 200 different households interviewed, about fifty nine percent (119) of them responded that they had engaged in migration before or were still currently involved in seasonal or circulation movements. Fifty percent (60) of them mentioned drought (locally called sanzali) as a reason for their migration.

The selection of the independent variables was based on some literature on migration and on earlier qualitative information gotten through interviews and focus group discussions. It is asserted that the individual characteristics and general socio-economic conditions of households including gender, age, income sources, education, and marital characteristics have an influence on the tendency to migrate during drought (Findley, 1994; Haug, 2002; Foresight, 2011). In terms of age, younger adults are more likely to migrate than older people and children when faced by environmental events (Castles \& Miller, 1993). In addition, households that depend on rain-fed agriculture as a major livelihood source are more likely to experience migration precipitated by drought (Brown, 2008; Dalby, 2009; Foresight, 2011). However, in this study all the households were engaged in farming as their major source of livelihood so their next most important source of income (minor source of income) was rather utilised in the analysis. In addition, educated or skilled people are more likely to migrate than uneducated or unskilled people (Castles \& Miller, 1993). Unmarried women are more likely to migrate than married women (Findley, 1994; Haug, 2002). Focus group discussions revealed that the availability of irrigation in one's village, the size of land in the irrigation area, size of land in 
drought prone area and size of land in flood prone area are important variables that influence drought-related migration. Irrigation enables all year cultivation of crops, improves farmers' income, and decreases their dependence on rain-fed farming. Having more land in droughtprone areas mean high susceptibility to drought effects so farmers also cultivate lands in flood prone areas to balance off the effects of drought as these areas maintain moisture for relatively longer periods.

\title{
Analytic approach
}

Qualitative data was segmented along thematic areas and fused into results of quantitative data discussions. Two analytical tools were used to analyse the quantitative data; first, a Chi-square test was used to test the statistical association between drought-related migration on one hand and the independent variables. Second, a binary logistic regression was employed to ascertain the level of association at a multivariate level between the dichotomous dependent variable and the independent variables.

\section{The role of drought in migration in the study area}

\begin{abstract}
Drought is a big problem...So we are aware it can come when God says so. So we must prepare for it. Only a fool...will not find and save something different from waiting for farm yields...look, you can buy fertilizer to take care of the goodness of the soil, but can you buy rain?...so some of the young men migrate every year to bring back something to support us...because only God knows when there will be drought. (Female, 45, Zaazi Village, focus group)
\end{abstract}

The statement highlights two important dimensions of livelihood; insecurity posed by drought risks and, migration as a key livelihood diversification strategy in response to recurrent drought. Livelihood insecurity emerging from drought is taken seriously by farmers in the study villages, not least for its surprise element and its potential diminution effects on yield. One of the key responses to drought among households is migration. Narrations provided by respondents on migration were replete with different roles of drought. These stories prompted a quantitative survey to help understand the broader context of drought-related migration. The migration experience of the respondents was explored. Out of the 200 individuals from 200 different households, 119 (59.5\%) of them had engaged in migration. The reasons for migration ranged from knowing the city to soil infertility as indicated in Figure 3. More than fifty percent of the respondents mentioned wealth accumulation as a reason for their migration(s). Bad 
harvest because of drought is the second highest reason for migration mentioned by a little more than half of respondents. This connection between drought and migration as revealed by the survey is very much in vogue with the narrations of respondents.

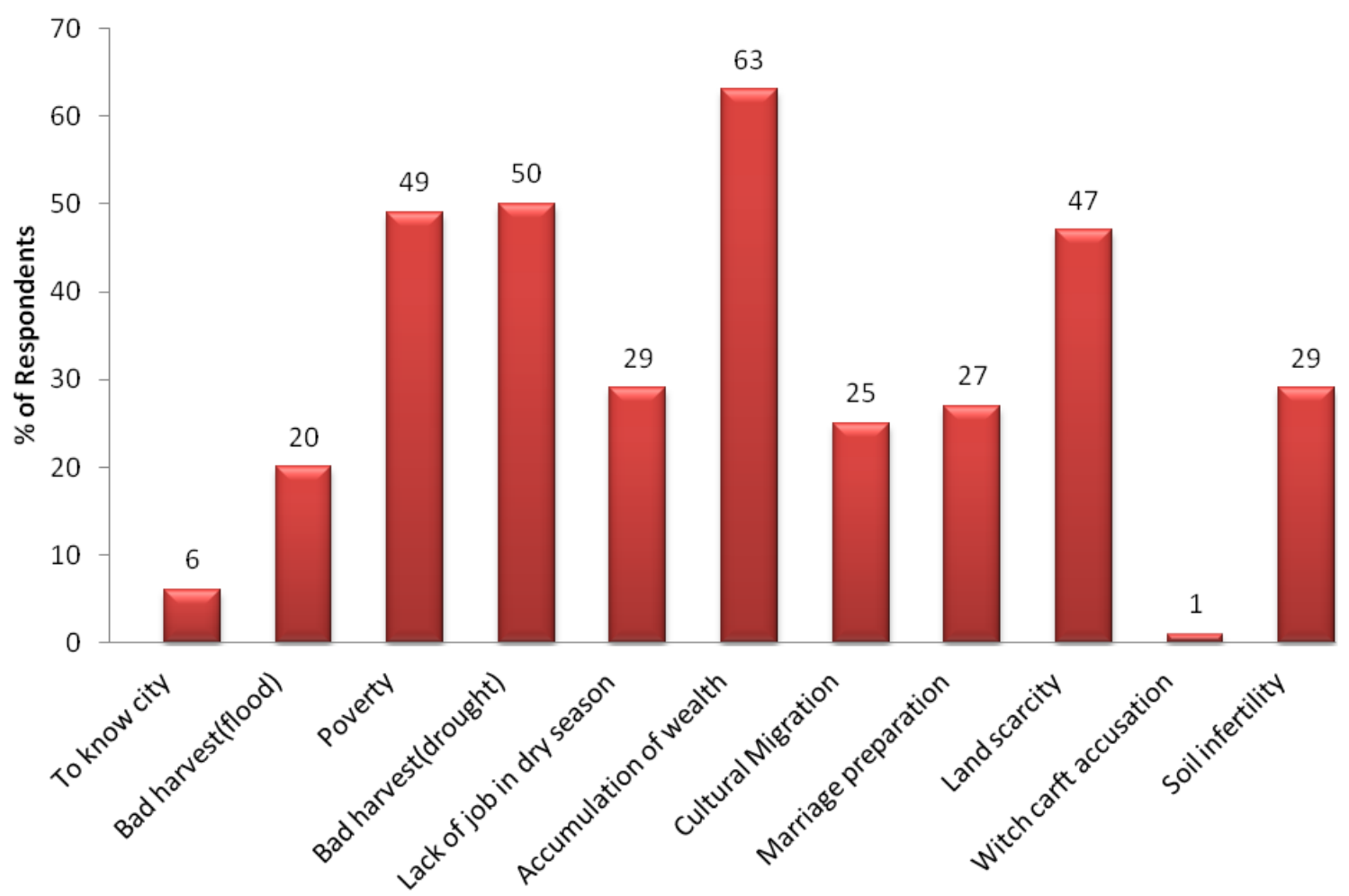

Figure 3. Reasons and motivations for migration

Focus groups and interviews point to the imperative of migration as a measure to deal with either anticipated or actual drought circumstances. Thus, migration in relation to drought is undertaken as a coping or adaptation strategy. Migration as a coping strategy emerges from the immediate and secondary effects of droughts. The immediate effects include low crop yield, low availability of wild foods and reduced water supply. The secondary effects of droughts include reduced farm labour wages, low returns to share harvesting, rise in food prices (speculation), rise in food prices (low yields), reduced financial capital and reduction in livestock. Migration as adaptation to drought on the other hand relates to what is referred to by this study as the tertiary effects of drought, which are the experience, and anticipation effect resulting from previous droughts. These allow for households and individuals to take on board long-term livelihood strategies such as seasonal and circular migration.

Spatially, drought-related migration in the study villages can be categorised into rural-urban and rural-rural migration. Rural to urban migration involves youths moving from their villages 


\section{Dynamics of Drought-Related Migration Among Five Villages in the Savannah of Ghana}

to urban locations particularly the major cities of Accra, Kumasi and Tema. These youths mostly engage in menial jobs including domestic and commercial work. Focus group discussions suggest that the majority engage in the commercial stream mainly as head porters and metal scrap dealers. Conversely, the rural-rural migration stream involves individuals, family units or entire families, moving to other rural areas on a seasonal basis to pursue agrarian livelihood strategies. This is exemplified by the practice of Kanako where mostly a man migrates with a part of or his entire family to take residence in another rural area with a better micro climate to pursue farming activities for the entire rainy season. It is however, stated by focus groups that this classic model of kanako is mainly practiced by the aged as it is less attractive to the youth who prefer a modernisation perspective to their mobilities. It is, also pointed out that the youth mostly migrate solely or in small groups of associates to rural areas in response to drought. They mostly go in search of farm labour in areas not affected by the drought. Indeed, focus group discussions emphasize that there is as much migration to rural areas as urban areas when faced by drought circumstances.

The results of the study further indicate that rather than a singular stream of migration, droughtrelated migrants commonly experienced multiple and intermittent rural to rural and rural to urban migrations. To ascertain the quantitative differentials between rural and urban destinations, respondents were asked to indicate the destinations of their drought-related migrations in the last ten years. The results showed that about ninety one (91.6\%) of them went to both rural and urban destinations in all the years they migrated because of drought. Urban destinations accounted for nearly fifty four percent (53.9\%) of all migration movements. Gender wise, a higher proportion of females were involved in both migration streams. Precisely, about eighty seven percent $(86.9 \%)$ of females were involved as opposed to about seventy percent $(70.2 \%)$ of males. This picture of the spatial aspects of drought-related migration in the study villages suggests a complex picture of how and when drought conditions results in a particular type of migration and for whom. The Foresight framework (2011) suggests differential influence on migration for different social groups. This is reflected in some scenarios provided by focus group discussions. For example, it is asserted that young males would usually first explore farm work opportunities in areas that did not experience the drought within the savannah to ensure they stay closer home or as a means of earning income to then travel to the city. In addition, most married women would normally go in search of harvesting opportunities in other areas within the savannah rather than going off to the city. This is to 
conform to social restrictions on their mobility as married women who are expected to perform their social reproduction responsibilities. Further, older men and women were more likely to go off to rural destinations to cultivate marshy areas that are more resilient to drought conditions than migrate to the city. These spatial aspects of drought-related migration contrast the narrow focus of the climate change literature on rural to rural migration in favour of rural to urban migration as a mobility outcome from climate conditions. Undoubtedly, this partly results from the growing importance of rural-urban migration in the livelihood repertoire of rural households in Africa (Ellis, 2000; Tacoli et. al., 2015) and the attention given by policy makers to the problems posed by rapidly growing urban populations (Jarawura \& Smith, 2015). Drought provides a trigger context, which allows for the mediation of all kinds of factors that may or may not result in a migration outcome (Foresight, 2011). This is the very reason not all households affected by drought will experience migration. This has also been the basis for refuting cause-effect hypothesis and of course, studies that attempt to predict number of persons likely to migrate from environmental shocks (Hummel, 2016). Considering the important role of mediating factors, the next section explores a range of factors to ascertain the extent of their mediation on drought-related migration.

\section{What factors mediate drought-related migration?}

Drought vulnerability circumstances are mediated by various demographic and socio-economic factors, which make up the micro space of vulnerability. Some of these demographic and socioeconomic characteristics include gender, marital status, level of education of respondents, age of respondent, age of household head, minor income of household, availability of irrigation in village, land size in irrigation facility, land in flood prone area, having more land in drought prone area, and having more land in flood prone area. Villages and households are differentiated by the nature of these characteristics. Thus, the effects of drought on migration will also be differentiated in respect to different households and individuals (Foresight, 2011). Table 1. shows the dependent variable, drought-related migration and non-drought related migration, and the independent variables. The independent variables are the selected characteristics of the 119 people who stated they had migrated at one time or another within the previous ten years. The cross tabulation and Chi-square test of association between droughtrelated migration on one hand and the independent variables on the other, reveals the extent of drought association with migration among respondents. 
Table 1: Percentage distribution of Individual characteristics by type of migration

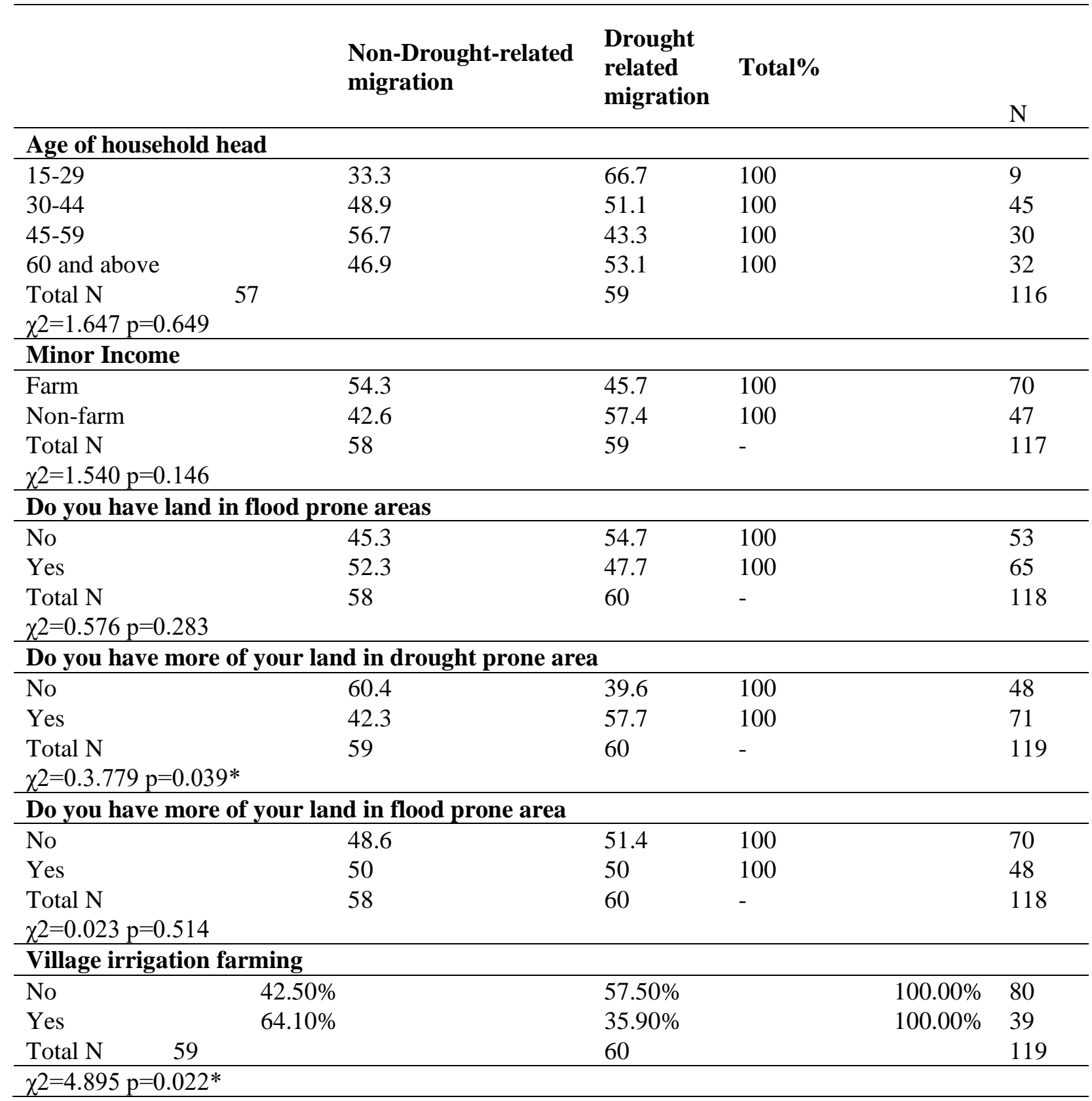


The results show that, although there is no significant relationship between the age group and the type of migration, a higher proportion of the individuals in the 10-14 age group (66.7\%) had experienced drought-related migration. However, there is a significant relationship between sex and the type of migration. Whilst a higher proportion of the females $(61.9 \%)$ had experienced non-drought-related migration, a little over half of the males (56.6\%) experienced drought-related migration. This is consistent with the assertions of focus group discussions that males normally migrate most in drought years as they are expected to salvage the associated negative conditions. There is no significant relationship between the level of education and the type of migration, and the same applies to the marital status. Table 2. shows the relationship between the dependent variable, drought-related migration and non-drought related migration, and the independent variables at the household and village level.

There was no significant relationship between the age of household head and the type of migration. The same applies to the source of minor income, having land in flood-prone areas, having more of land in flood-prone areas and how much land the household has in the irrigation facility. However, access to more land in drought-prone area is significantly related to the type of migration. Whilst a higher proportion of households with no land in drought-prone areas (60.4 percent) experienced non drought-related migration, more than half of households with more land in drought-prone areas (57.7 percent) had experienced drought-related migration. At the community level, there is a significant relationship between availability of irrigation farming in a village and type of migration. Whereas over half of the respondents from villages with no irrigation farming (57.5 percent) were inclined to drought-related migration, a higher proportion of the respondents from villages with irrigation farming (64.1 percent) were inclined towards non drought-related migration. 
Table 2: Percentage distribution of household and village characteristics by type of migration

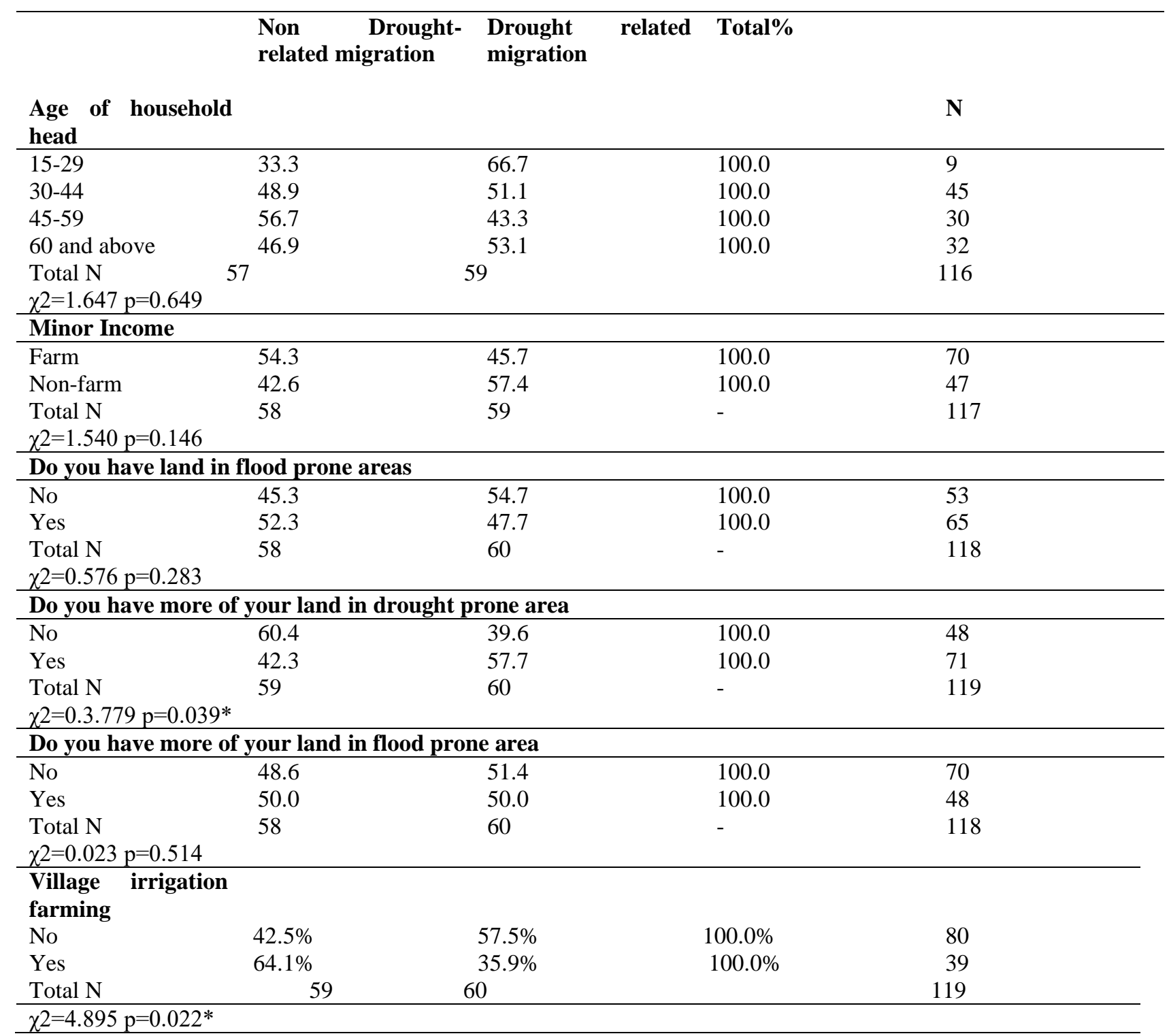

A binary logistic regression was performed to assess prediction of type of migration (dependent variable) as a function of the independent variables. The model, as shown in Table 2, explains 21.5 percent of the variation in type of migration. The age of the respondent was significantly associated with type of migration only at 90 percent confidence level. Respondents within the age group 30-44 were 0.138 times as likely as those in the reference category (10-14) to experience drought-related migration. There was also a significant association between sex of the respondent and type of migration. The males were 3.083 times as likely as the females to have experienced drought-related migration. In addition, there was a significant association between the source of minor income and type of migration, where respondents with non-farm 
minor income were 3.442 times likely to have drought related migration than those with onfarm minor income. In addition, respondents from households with more of their land located in drought-prone areas were 4.870 times than those without more of their land in drought-prone areas to have drought-related migration.

Also, worth noting is that households with more than one acre of land in irrigation facility were 9.621 times more than those with less than one acre of land in the irrigation facility to experience drought-related migration. Furthermore, respondents with household heads in the 45-49 age group were 0.090 times likely to have drought-related migration than those with household heads in the 15-29 age group. Finally, households in villages with irrigation schemes were 0.028 times less likely to experience drought-related migration than those in villages without irrigation farming. It is understood that irrigation has wider benefits that go beyond those directly engaged in dry season farming. This includes job opportunities on the farm and in processing of vegetables, and the general availability of cheap vegetables that boost food security in the village. Level of education, marital status and having land in flood-prone areas were not significantly associated with migration type in the model.

The influence of sex on drought-related migration as shown by the logistic regression is a corroboration of the assertions of focus groups discussions. They assert that males are more susceptible to migration under drought-vulnerability circumstances. This gender disparity is a result of the gender roles in these villages. Men are primarily responsible for providing food for the household whiles women are expected to perform household chaos and cater for children. Males are therefore expected to migrate in search of income to procure food for the household. Generally, migration of females is said to be largely unrelated to drought. These gender dimensions of drought-related migration are consistent with the findings of Findley (1994) from Mali and Ezra (2001) from Ethiopia. Obeng (2005) also found similar results in the north eastern part of Ghana.

The significance of availability of irrigation scheme in a village is understandable as irrigation enables the people in such villages to cultivate crops all year round. As a result, some old men in Libga make jokes that 'there is no drought in our village'. Focus group discussions pointed out that farming in the irrigation is tedious because tractors are not allowed in. This has ensured that household heads restrict young people who wish to migrate as a way of maintaining the needed household labour. More so, there are claims that older youth who have autonomy over inherited plots in the irrigation scheme still find the returns from dry season irrigation farming more rewarding than returns from migration. 
Table 3: Binary Logistics Regression Parameter estimation of the model on individual, household and community characteristics and Type of migration

\begin{tabular}{|c|c|c|c|c|}
\hline Variables & $\begin{array}{l}\text { Coefficients } \\
\text { (Beta) }\end{array}$ & Standard Error & Significance & Odds Ratio \\
\hline Age & & & & 1.000 \\
\hline $10-14(\mathrm{RC})$ & & & & 0.171 \\
\hline $15-29$ & -1.763 & 1.011 & 0.081 & 0.138 \\
\hline $30-44$ & -1.975 & 0.982 & 0.044 & 0.300 \\
\hline $45-59$ & -1.203 & 1.167 & 0.303 & 0.147 \\
\hline 60 and above & -1.917 & 1.150 & 0.096 & \\
\hline \multicolumn{5}{|l|}{ Sex } \\
\hline Female (RC) & & & & 1.000 \\
\hline Male & 1.126 & 0.484 & 0.020 & 3.083 \\
\hline \multicolumn{5}{|l|}{ Level of Education } \\
\hline None (RC) & & & & 1.000 \\
\hline Primary & -1.467 & 0.540 & 0.577 & 0.231 \\
\hline JHS & -2.410 & 0.733 & 0.598 & 0.090 \\
\hline SHS & 1.208 & 1.090 & 0.268 & 3.347 \\
\hline \multicolumn{5}{|l|}{ Marital status } \\
\hline Not in union (RC) & & & & 1.000 \\
\hline Currently in union & -0.462 & 0.481 & 0.337 & 0.630 \\
\hline \multicolumn{5}{|l|}{ Age of household head } \\
\hline $15-29$ & & & & 1.000 \\
\hline $30-44$ & -1.467 & 0.872 & 0.092 & 0.231 \\
\hline $45-59$ & -2.410 & 0.875 & 0.006 & 0.090 \\
\hline 60 and above & -0.812 & 0.898 & 0.366 & 0.444 \\
\hline \multicolumn{5}{|l|}{ Minor income } \\
\hline Farm (RC) & & & & 1.000 \\
\hline Non-farm & 1.236 & 0.545 & 0.023 & 3.442 \\
\hline \multicolumn{5}{|l|}{ Land in flood-prone area } \\
\hline Yes & & & & 1.000 \\
\hline & -0.810 & 0.564 & 0.151 & 0.445 \\
\hline \multicolumn{5}{|l|}{$\begin{array}{l}\text { More of land in drought- } \\
\text { prone area }\end{array}$} \\
\hline No $(\mathrm{RC})$ & & & & 1.000 \\
\hline Yes & 1.583 & 0.616 & 0.010 & 4.870 \\
\hline \multicolumn{5}{|l|}{$\begin{array}{l}\text { More of land in flood-prone } \\
\text { area }\end{array}$} \\
\hline No $(\mathrm{RC})$ & & & & 1.000 \\
\hline Yes & 0.915 & 0.735 & 0.213 & 2.497 \\
\hline \multicolumn{5}{|l|}{$\begin{array}{l}\text { Household land in irrigation } \\
\text { facility }\end{array}$} \\
\hline Less than one acre (RC) & & & & 1.000 \\
\hline More than one acre & 2.264 & 1.111 & 0.042 & 9.621 \\
\hline \multicolumn{5}{|l|}{ Village irrigation farming } \\
\hline \multicolumn{5}{|l|}{ No $(\mathrm{RC})$} \\
\hline Yes & & & & 1.000 \\
\hline & -3.587 & 1.169 & 0.002 & 0.028 \\
\hline Constant & 1.734 & 1.304 & 0.184 & \\
\hline Model $\mathrm{R}^{2}$ & 0.215 & & & \\
\hline
\end{tabular}

The result on the relationship between the size of irrigated land and drought-related migration is rather intriguing. A follow up qualitative data collection revealed that at the time of land 
distribution at the irrigation facility, households with more matured males were given between one and two acres of land while those with lesser males were given less than an acre. Focus group discussions reveal that although some households had several times more males, they were given no more than two acres of land. Accordingly, the unintended consequence of this allotment was that in many cases households with smaller number of males practically got more land than those with larger number of males. The explanation follows that most of the households with more males have increased in their household sizes overtime faster than those with less males resulting in pressure on their allocations. This is said to have contributed to the migration of particularly their males in search of alternative income sources. Besides, proceeds from the irrigated farms are said to be largely controlled by the household heads and used for household needs. This is said to be contrary to the aspirations of particularly younger men and women who have aims to acquire modern wares and to accumulate some wealth. Further, rivalries among particularly stepsibling in the households with more males resulted in more migration in search of alternative sources of income.

Focus groups discussions and individual interviews further highlight the critical mediation role of individual aspirations, networks and spirituality in drought related-migration. Individual aspiration is considered a key decision-making variable particularly among the youth (Foresight, 2011). The interplay of these factors with household and individual characteristics reflects a complex landscape of drought-related migration decisions. For instance, the story is told of young people who see drought circumstances as opportunity to migrate as highlighted in the following statement:

In the dry season you hardly see any girls here. The young boys used to play with them in the daytime and at night during moonlight with drums and dance. But where are they? They are gone [... ] so the boys too go after them even if their parents don't allow, they just wait for a time of bad harvest [...] Even the boys and girls who are too small to go, go without their parents notice but their parents don't pull their ears so much on return if they don't bring debts (Male70, Kpalung village, focus group).

Beyond the quest to know the city, created partly by the demonstration effect of return migrants and depictions of the city in pictures and visual media, there are other motivations and pull factors for migrating under drought circumstances. These include the zeal to find their girlfriends that had already left the village, and to find partners for marriage. In earlier studies, Rao (1993) and Anderson (2003) asserted that drought could hinder marriage related migration by reduction in availability of suitable marriage partners as both males and females migrated. What is perhaps fascinating about the situation in the five villages is that young men went after 
their girlfriends not necessarily to find them for marriage purposes but to have fun. Respondents also linked this 'happy moment' provided by drought circumstances to young men who were in search of an opportunity to leave the village to pursue skill learning in other livelihood strategies. Several return migrants stated they utilised migration opportunities provided by drought circumstances to leave the village and learn skills such as carpentry and masonry. A particular case worth mentioning is that of a household head who explored such a drought opportunity to migrate to Techiman in southern Ghana to learn how to repair motorcycles. The opportunity was unique to him because as a household head, it is not expected of him to migrate except under dire conditions. After three years the young man returned to his village and begun working on motorcycles to earn income. The young man who unequivocally explains the fulfilling nature of his drought-related migration had this to say:

I always wanted to do something with machines when I saw that many people were buying them but I never got the chance to leave the village after I build my own house and became the household head. Today I feel I am doing what I like to do.

This and other such narrations highlight the simple fact that rural people have aspirations that transcend the agrarian scope of livelihood possibilities. These aspirations may be spurred by the changing landscape of development in rural areas as their standards of living are uplifted in different ways. This is against long standing traditional notions of rural development that emphasized just appropriate agrarian developments.

Spirituality also plays a key role in migration under drought conditions. Many respondents who had migrated before or still in the process stated their partial dependence on outcomes of consultations with spiritualist about how to deal with a drought and also if an intended migration would turn out positive as reflected in the following statement:

During drought those who want to migrate...normally check to see how things are and perform some sacrifices before they migrate, if your migration will not help you, they will see it and help you with some charms or you don't migrate at all and try another thing (25 year old return male migrant, Kpalung village).

If the 'magic man' saw that their migration wasn't going to be worthwhile, then they either performed sacrifices to make it good or they abandoned the option and tried other strategies. It is further explained that increasingly more females as compared to males are consulting the oracles and getting charms to help with their migration. Their peculiar vulnerabilities in the destination including exploitation and sexual assault may partly explain this sudden surge in 
consulting oracles before migration among females. The spiritual element in migration decisions under drought conditions adds to the basket of factors that make simple cause-effect notions on environmental drivers and migration unacceptable.

\section{Conclusion}

This paper has demonstrated that drought plays an important role in rural out-migration in the savannah of northern Ghana. Spatially, in the study area, drought related migration is much about rural to rural migration as it is about rural to urban migration. The latter process is given more prominence in the climate-migration debates and policy circles, as corroborated by previous studies (Foresight, 2011; Jarawura \& Smith, 2015). This is not surprising given the long existing concerns on rising immigration in major cities; particularly, as related to employment security, accommodation needs, and access to basic amenities. The failure to recognise rural to rural migration as one of the migration forms influenced by climate change parameters as drought could lead to a neglect of rural spaces as recipients of climate-related migrants in climate policies and strategies. It is thus imperative for scholars and policy makers to further consider the intricacies of climate-induced rural to rural migration.

The paper further highlights the complexity of the relationship between drought and migration. While the importance of drought for migration is easily discernible from the data presented by the paper, it is rather difficult to point to and unravel the individual role of the factors that mediate migration outcomes under drought conditions. This is reflected in the complex interplay of factors in the events and processes leading to migration from the accounts of respondents and from the statistical analysis conducted. The binary logistic regression model for example shows that only $21.5 \%$ of drought-related migrations can be explained by the selected variables. Explaining the linkages between the environment and human migration has always being a difficulty and requires closer attention to the drivers of migration (Black, 2011; Adaawen et al., 2019). This suggests the need for a search for additional range of quantitative variables that could help explain drought-related migrations among agrarian households. This

probably could be achieved by making a careful selection of qualitative variables and finding quantitative proxies for them, employing a framework as broad as that of the Foresight. For example, while this study qualitatively highlights the critical role of opportunity and individual aspirations, it fails to find corresponding quantitative variables for these thus diminishing the potential to achieve a wider range of contextual explanatory variables. 
This study shows the influential mediating role of various idiosyncrasies including gender, the availability of irrigation in a village and a household's location of land in drought-prone areas, networks, and individual aspirations. Previous studies have found these factors influential in the decision to migrate under drought conditions (Findley, 1994; Schoumaker \& Beauchemin, 2004; Hummel, 2016). In this study, the role of availability of irrigation and individual aspirations draw attention to the need to recognise accessibility of different household members to irrigation than merely that of the household, and the aspirations of different individuals. Gender wise, the findings of males being several times more likely as females to experience drought-related migration reflect the patriarchal nature of northern Ghana, which makes it expedient for males to provide for their households. Previous studies have found the cultural characteristics of migration as crucial in understanding the mediation processes leading to migration under different climate conditions (Liehr et al., 2016). Social restriction on mobility of married females in the study area is another reason for the male dominance of droughtrelated migration. As Adger et al. (2009) and Gioli et al. (2014) note, responses to climate perturbations are partly dependent on social restrictions on different individuals. This is crucial in the decision to migrate when faced by environmental challenges. The study further points to the need to reconsider the narratives of rural out-migrants as necessarily victims of environmental challenges or of the lack or limited income opportunities, or the 'loneliness' of the long dry-season. The multiplicity of factors and the complexity of their interaction clearly highlight the need to shift away from earlier simplistic and deterministic notions of the climatemigration nexus. 


\section{References}

Adaawen, S., Rademacher-Schulz, C., Schraven, B., \& Segadlo, N. (2019). Drought, migration, and conflict in sub-Saharan Africa: what are the links and policy options?. Current Directions in Water Scarcity Research, 2, 15-31.

Adger, W. N., Dessai, S., Goulden, M., Hulme, M., Lorenzoni, I., Nelson, D. R., et al. (2009). Are there social limits to adaptation to climate change? Climatic Change, 93(3-4), 335354.

Anderson, S. (2003). Why dowry payments declined with modernization in Europe but are rising in India. Journal of Political Economy 111(2): 269-310.

Bening, R.B. (1975). Colonial development policy in northern Ghana, 1898-1950. Bulletin of the Ghana Geographical Association, 17.

Black, R., Bennett, S. R., Thomas, S. M., \& Beddington, J. R. (2011). Climate change: Migration as adaptation. Nature, 478(7370), 447.

Brown, O. (2008). Migration and Climate Change. International Organisation for Migration Research Series, ISSN 1607-338X.

Castles, S., \& Miller, M. J. (1993). The age of migration: International population movements in the modern world. Basingstoke: Macmillan.

Cleveland, D.A. (1991). Migration in West Africa: A Savanna Village Perspective. Africa, 61(2), 222-246.

Dalby, S. (2009). Security and Environmental Change. Cambridge: Polity Press.

Derbile, E. K., Jarawura, F. X., \& Dombo, M. Y. (2016). Climate change, local knowledge and climate change adaptation in Ghana. In Adaptation to climate change and variability in rural West Africa (pp. 83-102). Springer, Cham.

Devereux, S. (2000). Famine in the twentieth century. Institute of Development Studies, Working Paper, 105.

Dietz, T., Millar, D., Dittoh, S., Obeng, F., \& Ofori-Sarpong, E. (2004). Climate and livelihood change in North East Ghana. In The impact of climate change on drylands (pp. 149-172). Springer, Dordrecht.

Ellis, F. (2000). Rural livelihoods and diversity in developing countries. Oxford university press.

Ezra, M. (2001). Demographic responses to environmental stress in the drought- and famineprone areas of northern Ethiopia. International Journal of Population Geography 7(4), 259-279.

Findley, S.E. (1994). Does Drought Increase Migration? A Study of Migration from Rural Mali during the 1983-1985 Drought. International Migration Review, 28(3), 539-553.

Foresight, (2011). Final Project Report: Migration and Global Environmental Change London, The Government office for Science.

Ghana Environmental Protection Agency. (2012). Climate Change Impact: Why Must Ghana Worry? Policy Advice Series 0, Accra: Environmental Protection Agency.

Ghana Statistical Service (GSS), (2018). Ghana Living Standards Survey Round 7 (GLSS7): Main Report, Accra: Ghana Statistical Service.

Gioli, G., Khan, T., Bisht, S., \& Scheffran, J. (2014). Migration as an adaptation strategy and its gendered implications: A case study from the Upper Indus Basin. Mountain Research and Development, 34(3), 255-265.

Gray, C. L., \& Mueller, V. (2012). Natural disasters and population mobility in Bangladesh. Proceedings of the National Academy of Sciences, 109(16), 6000-6005.

Haug, R. (2002). Forced migration, processes of return and livelihood construction among Pastoralists in Northern Sudan. Disasters, 26(1), 70-84. 
Hugo, G. (1996). Environmental concerns and International Migration. International Migration Review, 30(1), 105-131.

Hummel, D. (2016). Climate change, land degradation and migration in Mali and Senegalsome policy implications. Migration and Development, 5(2), 211-233.

Intergovernmental Panel on Climate Change (IPCC) (2013). Climate Change 2013: The Physical Science Basis, Contribution of Working Group I to the Fifth Assessment Report of the Intergovernmental Panel on Climate Change (Cambridge: Cambridge University Press).

Jarawura, F. X., \& Smith, L. (2015). Finding the right Path: Climate change and migration in Northern Ghana. In Environmental Change, Adaptation and Migration (pp. 245-266). Palgrave Macmillan, London.

Krokfors, C. (1995). Poverty, Environmental Stress and Cultures as Factors in African Migrations. In The Migration Experience in Africa (pp. 54-64). Sweden: Nordiska Afrikainstitutet.

Liehr, S., Drees, L., \& Hummel, D. (2016). Migration as societal response to climate change and land degradation in Mali and Senegal. In Adaptation to Climate Change and Variability in Rural West Africa (pp. 147-169). Springer, Cham.

Obeng F.K. (2005). Things are hard for us we see a way out of them: Impact of climate variability on geographical and occupational mobility and the effect of mobility on social organisation in farming communities in North-East Ghana. Amsterdam. Amsterdam Institute for Metropolitan and International Development Studies.

Rao, V. (1993). The rising price of husbands: A hedonic analysis of dowry increases in rural India. Journal of Political Economy 101(3): 666-677.

Schoumaker, S.B.H., \& Beauchemin, C. (2004). The Impact of Rainfall on the First OutMigration: A Multi-Level Event-History Analysis in Burkina Faso. Population and Environment, 25(5), 423-460.

Tacoli, C., McGranahan, G., \& Satterthwaite, D. (2015). Urbanisation, rural-urban migration and urban poverty. Human Settlements Group, International Institute for Environment and Development.

Thiede, B., Gray, C., \& Mueller, V. (2016). Climate variability and inter-provincial migration in South America, 1970-2011. Global Environmental Change, 41, 228-240.

Van der Geest, K. (2011). North-South Migration in Ghana: What Role for the Environment. International Migration, 49(sl), e69-e94.

Yaro, J. A. (2013). The perception of and adaptation to climate variability/change in Ghana by small-scale and commercial farmers. Regional Environmental Change, 13(6), 12591272.

Yaro, J. A., Teye, J. K., \& Bawakyillenuo, S. (2016). An assessment of determinants of adaptive capacity to climate change/variability in the rural savannah of Ghana. In Adaptation to Climate Change and Variability in Rural West Africa (pp. 59-82). Springer, Cham. 